\title{
Editoríal
}

\section{THE BORDERLAND PATIENT.}

RETIVEEN the undisputed realms of neurology and psychiatry Blies a province in which both parties claim an interest and a right. It comprises that whole group of patients whose symptoms are truly of a mental order but of a degree which does not demand institutional care. Here are the high-grade mental defectives, the psychoneurotics and the psychotics. The last-named are perhaps not the least numerous. Some of them are in the early stages of what is really a severe psychosis. These will eventually pass over the border into the realm of the psychiatrist. Others are mild psychotics. Though from the medical standpoint they may be suffering from serious mental illness they are not, nor do they ever become, so completely incapable of social adjustment that they may be deemed legally of unsound mind.

The claim of the psychiatrist to this disputed province is based upon the fact that these are one and all cases of mental disorder. In theory there is no reply to the argument. In practice the situation is different. The majority of these cases do not come within the ken of the psychiatrist for the simple reason that they are not such as demand institutional care, and the psychiatrist, both by training and opportunity, has hitherto been largely restricted to the observation of institutional cases. The fault lies in the system, and the system is traditional. The care of the insane in institutions became a problem of necessity long before the profession or the public took any interest in the ætiology and treatment of mental disorder in general. Hence the psychiatrist-whose long years of asylum experience give him an insight into the control, the management, the care, and the symptomatic treatment of mental disorder in its certifiable stages, which can be obtained in no other way, but whose outlook upon the problem of mental disorder as a whole is obscured by the limited perspective of his training.

The claim of the neurologist to deal with the borderland patient is generally based upon practical considerations. As a specialist in nervous diseases, he is constantly being called upon to see and treat these cases. The reason again is as simple as it appears foolish. By means of that particular kind of selfdeception, which is so justly derided in the ostrich, both public and profession have blinded themselves to the 
fact that these are cases of mental disorder. The layman speaks of ' nerves,' the profession of 'functional nervous disorder.' Therefore it is to the neurologist that these patients come and are sent. Their movement in this direction is assisted by fear of the psychiatrist on account of that same tradition to which we have already referred. The psychiatrist is the physician who looks after persons in asylums. . . .

The neurologist, for his part, is often poorly equipped for dealing with them. He is as a rule interested primarily in problems of organic disease, and lacking in psychiatric experience. His attitude towards the case of minor mental disorder may be, "Another of these tiresom: neurasthenics!" Or he may take an interest in them and learn. If so, he will have plenty of clinical material to hand, but his lack of intimate experience of the advanced types of mental disorder renders him liable always to miss the mild or early psychotis. How many cases of mild schizophrenic or manic-depressive psychosis have been seen and erroneously diagnosed by a neurologist before finding their way to a psychiatrist? Many of the non-progressive psychotics remain concealed by the label 'neurasthenia' and never reach the psychiatrist at all.

The ultimate remedy for this state of affairs will be a widening of the psychiatric outlook. We may expect in the future that the care of the insane in institutions will be regarded as a still important, but relatively small, part of the training of a consultant in psychiatric medicine, and that outpatient clinics, with provision for in-patient treatment on a voluntary basis, will occupy the greater part of his time. Such clinics may be established at the general hospitals or as independent units. The Maudsley Hospital provides an excellent example in this country of what may be done in the latter direction.

Meanwhile, we need a closer co-operation between neurologist and psychiatrist, both in hospital and in private practice. The establishment of neuropsychiatric clinics at the teaching hospitals in which neurologist and psychiatrist work together in close conjunction is a step in the right direction. From such symbiosis should come a clearer understanding of the many problems at issue and better provision for the borderland case. 